\title{
De dioses y monstruos Francisco Hernández, heredero de la tradición del delirio
}

José Eduardo Serrato Córdova

Gl libro Moneda de tres caras (1990) de Francisco Hernández es Cun hito dentro de la historia de la poesía mexicana pues toca un tema poco frecuente dentro de la retórica nacional, la demencia y el delirio en la poesía. Temática que nos lleva directamente a lo irracional y su función en la ética y la estética contemporánea. El poemario gira en torno de la estética de tres autores que sufrieron de serios problemas psiquiátricos: Schumann, Hölderlin y Georg Trakl. Las tres variaciones poético-biográficas se inspiran en los delirios de estos artistas. Cabe preguntarnos cómo es que el artista "traduce" y asimila el lenguaje de lo irracional o la poética visionaria a su horizonte cultural.

La poesía visionaria ha sido motivo de los grandes libros de Northrop Frye, Harold Bloom y de Roberto Calasso. Poesía que nace de la revelación y que es de la misma ascendencia que los textos de San Juan de Patmos. Ahora bien, ¿qué tipo de revelaciones encontramos en estos poetas? Naturalmente no son profecías al estilo Nostradamus ni anuncios de desastres culturales. Las revelaciones de estos poetas del delirio son de tipo filosófico y más exactamente de la metafísica, en tanto que son poemas que hablan del ser, del tiempo, de lo absoluto y de la divinidad misma. No es casualidad que encontremos 
asombrosos paralelismos entre la poesía visionaria y el lenguaje de los místicos.

Francisco Hernández retoma el tópico romántico de considerar el mundo como un mundo de correspondencias secretas para hablar en lenguaje cifrado de los delirios místicos tanto de Robert Schumann como de Hölderlin, en cambio hace una recreación simbólica de la agonía de Trakl haciendo una especie de descenso al corazón de las tinieblas en medio de un infierno tropical lleno de simbolismos poéticos.

"Marcados por el fuego", kerygmáticos o maniaco-depresivos son los calificativos que estos poetas han recibido a lo largo de la historia. Hagamos un repaso de este tipo de estigma existencial que distingue a estos visionarios. Tomo el libro Moneda de tres caras como un pretexto para referirme a la larga y egregia tradición poética que precede la obra de Francisco Hernández.

\section{¿Podría ser esto locura?}

Hay dos palabras incómodas en la historia de la cultura: locura e irracional. Nos llamó la atención el desprecio que muchos críticos y lectores tenían hacia lo irracional en el arte. Poco serio, falta de imaginación, tomadura de pelo, pésimo gusto son algunos sinónimos que nos encontramos cuando se quiere definir lo "irracional". Fernando Corripio en su Diccionario de Ideas Afines consigna como sinónimos de irracional: ilógico, absurdo, incongruente y disparate. La palabra es, en la actualidad, casi un insulto. Despreciada por filósofos y utilizada más por psicólogos como una patología, la palabra se encuentra en estado latente en el símbolo poético en espera de que alguien se aventure a escarbar en su tumba. Tumba sin sosiego, porque a pesar del menosprecio que tiene en el ámbito del saber, nos encontramos que hay una enorme tradición, casi una historia oculta detrás del adjetivo "irracional". 
Durante la investigación nos encontramos con que muchos poetas se han fascinado con la locura, tanto real como ficticia, todos desarrollaron una retórica de la locura como una forma de protesta social o cultural. Encontramos, en primer lugar, que la locura como sinónimo de lo profético tiene una larga tradición. Durante más de quinientos años, Occidente ha creído en la fuerza de la razón práctica. Hemos sido educados para ser razonables. Resolvemos nuestros problemas recurriendo a la razón, lo racional es sinónimo de lo real y auténtico. Valoramos nuestra existencia por nuestras coherencias y nuestra integridad, es decir, por nuestra vida racional. Desconfiamos de lo irracional, la incoherencia no tiene cabida en ningún proceso cognoscitivo. La demencia ha sido confinada al hospital psiquiátrico, es un padecimiento mental en el que el paciente es aislado del mundo de los cuerdos. El arte que se interesa por el aspecto de las enfermedades mentales es visto con desconfianza o cuando mucho como un recurso del humor grotesco. Decimos, pues, que lo irracional ha sido un cajón de sastre en el que nuestra cultura ha encerrado lo que no conviene a los intereses de la razón práctica de la modernidad. Lo inexplicable, los monstruos de la razón se han refugiado, entonces, en el arte en general.

Para nuestra revisión de la expresión irracional y sus sinónimos, tenemos que remitirnos a la historia de su hermana siamesa, la razón. El imperio de la razón ha tenido varias épocas, desde el triunfo del racionalismo aristotélico hasta el racionalismo positivista de la era moderna. Hans Georg Gadamer nos recuerda en Mito y razón que al inicio del descubrimiento de la razón por los griegos, Platón desacreditó los mitos por su "irracionalidad". Posteriormente, la razón que relegó al mito al ámbito no vinculante de la imaginación lúdica fue expulsada rápidamente de su posición de mando. Si echamos una ojeada a la formación de la civilización occidental, el impulso ilustrado parece haber tenido en la historia tres grandes oleadas: la oleada ilustrada que culmina con la sofística radical ateniense del tardío si- 
glo $V$ antes de nuestra era; la oleada ilustrada del siglo XVIII que tuvo su punto culminante en el racionalismo de la Revolución Francesa y, así se debería decir quizá, el movimiento ilustrado de nuestro siglo que ha alcanzado la cumbre provisional en la "religión del ateísmo" y su fundación institucional en los modernos ordenamientos estatales ateos. El problema de lo fantasioso irracional está soterrado en la historia del racionalismo triunfante.

Señala Roberto Calasso (2001) que lo mítico y lo irracional aparecieron en dos libros pioneros del tema: La historia de los mitos del mundo antiguo, de Josef Görres, y Simbólica de Creuzer. La apelación a lo instintivo e irracional del mito llevó a la generación de Schelling, Hegel y Hölderlin a revalorar la mitología griega y a estudiar la religión popular. Poetas y filósofos consideraron revalorar religión, mitología y ciencia con el fin de conciliar lo irreconciliable. No faltaron poetas audaces que intentaron fundar una nueva religión basándose en una nueva hermenéutica de los textos sagrados y en la poesía de creación absoluta. Este legado nos ha llegado hasta nuestros días sin que tengamos la menor idea de la gran aventura cultural que se puso en movimiento. Ya Nietzsche nos había advertido en El nacimiento de la tragedia que: "He aquí nuestra era [...] volcada al exterminio del mito. El hombre de hoy, despojado del mito, se yergue famélico sobre su propio pasado y debe escarbar frenéticamente buscando sus raíces entre las remotas antigüedades".

Naturalmente, una nueva mitología estética, que fuera mitología de la razón y, al mismo tiempo, consiguiera unificar armónicamente la parte espiritual y la parte sensible de la religión, no llegó a ser más que un programa. Sin embargo, el denominado "programa de sistema”, que formuló este ideal y que fue seguramente un fugaz trabajo privado -fuese quien fuese su autor- había expresado una verdadera necesidad de la época. El mito del socialismo (Saint-Simon), el mito de la violencia (Sorel) y otras ideologías políticas, que se resguardaban en el nimbo de lo religioso, lo comprueban. Estas utopías se ges- 
taron en visiones proféticas que nacieron en un estado de euforia, en el que fue revelado el mensaje sagrado. Sería oportuno repasar la idea de trance poético y de locura desde el punto de vista de los poetas.

Detengámonos a revisar el concepto de locura, manía o arrebato sagrado que Platón comenta en el Fedro, y del que Sócrates mismo fue presa. Calasso $(2002,2004)$ ha rastreado las manifestaciones de la "manía” desde la edad clásica hasta el siglo XX, Platón establece la diferencia del arrebato producido por los dioses en los hombres sensibles. Pero encontramos desde Homero la palabra clave de la locura que proviene de la posesión sagrada del dios. La manía y la posesión son las dos formas en que la revelación se manifestó entre los griegos. El conocimiento de la manía está simbolizado por la fuente, la serpiente y la ninfa, estos tres entes tienen en común la mirada vigilante -la fuente es una suerte de ojo insomne- y la posesión de la voluntad del hombre. Calasso hace la gramática histórica de la posesión como arrebato poético o como locura, pero específicamente de la nympholeptoi y el theoleptoi. Dice en su Ética a Eudemo: “quizá la felicidad puede venir a nosotros [...] como ocurre a los nympholeptoi y a los theoleptoi, que entran como en una ebriedad (enthousiazontes) por inspiración de un ser divino, o bien a través de la fortuna (muchos, en efecto, dicen que la felicidad y la fortuna son la misma cosa)" (Calasso, 2004: 27). El ensayista italiano nos recuerda que la imagen moderna de la posesión depende en gran parte aún, si bien no se lo admite, del ocultismo decimonónico. Son bocas espumosas o brujas glosolalistas o rubias satanistas feroces las primeras referencias que afloran, hasta Eric Dodds, en Los griegos y lo irracional, legitimó los aspectos parapsicológicos de los textos platónicos y órficos. Fue entonces que el concepto de posesión tomó carta de ciudadanía en el mundo del conocimiento. Durante el romanticismo, el arrebato de las ninfas se manifestó de nuevo. Muchos de los poetas que fueron picados por el abejorro de Dioniso o de Apolo acabaron en el manicomio. La "manía” sagrada se convirtió en una palabra clínica que 
designaba un transtorno mental. Lo importante de este resurgir es que los poetas iniciaron el culto a la "locura divina".

\section{Poética del "entusiasmo"}

\section{El ojo ve más de lo que sabe el corazón William Blake}

A finales del siglo XVIII, en Inglaterra, poesía y locura eran palabras sinónimas. El caso del poeta Cowper es representativo del mal. Cowper fue contemporáneo de Blake y dedicó toda su juventud a la poesía y a la lectura de la Biblia. Murió en la ruina y presa de la enfermedad del siglo: la melancolía. Diecinueve años después de la muerte de Cowper, William Blake, fascinado por un pasaje sobre la manía religiosa que leyó en un libro de Spürzheim, titulado Observaciones sobre las manifestaciones dañinas de la mente o locura (Observations on the Deranged Manifestations of the Mind, or Insanity, 1819), escribió en alguna ocasión que "La locura es un refugio de lo increíble". Blake, como Cowper, encontró en la locura un escape, una forma de vida que acogió con todos sus terrores. Blake se reveló contra la imposición del saber académico, por eso juzgaba que sus enemigos naturales eran Bacon, Newton, Locke y, sobre todo, Sir Joshua Reynolds, presidente de la Real Academia. Blake nunca imaginó que Newton era secretamente un seguidor de la filosofía ocultista, al que socialmente le convenía el título de padre de la física moderna. Newton reprimió cualquier manifestación personal que revelara un acercamiento a lo "irracional", sabía la importancia de suprimir lo onírico y lo demencial que hay en la conducta humana.

A finales del XVIII y principios del XIX, la locura había atraído la atención del público, así como una buena dosis de incertidumbre. Aclaremos de una vez que cuando nos referimos a la locura empleamos el término en el sentido antiguo, que se ha perdido con el em- 
pleo clínico de la palabra. Locura define cualquier forma de alienación ya sea del comportamiento o de la percepción. Es oportuno que el lector haga una distinción entre el concepto actual de locura y el del siglo XVIII. Sería cruel decir que la demencia, tal como la concebimos hoy día, objeto de angustias y depresiones, sea la misma que causó furor entre los escritores del periodo de 1750 a 1850 . Cuando nos referimos en este trabajo a la "locura", hacemos alusión más bien a una cierta idea de "locura literaria" que tiene que ver más con una forma de protesta de las intolerables condiciones sociales de la industrialización y con el triunfo apabullante del racionalismo que con una discapacidad mental. En este trabajo, como en el romanticismo, a la palabra locura le agregamos una carga semántica extra: fuente de energía creadora.

La demencia de Blake fue diferente a la de Cowper, fue una locura basada en su temperamento sanguíneo y en su indignación contra la Academia inglesa. A finales del XVIII y a principios del XIX, la locura tuvo su encanto y sus miserias. El 9 de junio de 1796, el joven Charles Lamb escribió a su amigo Samuel Taylor Coleridge una carta en donde le narra el breve periodo que pasó en el manicomio: "Veo esos años con una especie de envidia. Por un rato disfruté de muchas horas de pura felicidad. No desvarío, Coleridge, hasta que llegué a la demencia probé la grandeza y la salvajez de la fantasía. Ahora todo me parece insípido, comparado con aquellos días" (Rosen, 1998: 113). Para Lamb la locura trajo color y emoción a su monocroma vida, quizá también aludía al lugar común que el Werther de Goethe puso de moda en el romanticismo, y aludía a la escena en donde un joven extravagante le confiesa al héroe que hubo un tiempo en que fue feliz como pez en el agua, entonces su madre revela que dicho periodo ocurrió cuando el joven estuvo encadenado en un hospital psiquiátrico.

Podemos decir que para los románticos la demencia era síntoma de buena salud. Nerval escribió al inicio de Aurelia: "Traté de trans- 
cribir las impresiones de una larga enfermedad, la que ocurrió en los misterios de la mente -y no sé por qué empleo la palabra enfermedad, si nunca, según recuerdo, me sentí tan sano". En una carta del 9 de noviembre de 1841, dirigida a la esposa de Alexandre Dumas, Nerval agregó: "Sólo me dejarán salir [del manicomio] si me convierto en gente razonable y acepto que estuve enfermo, lo cual me hará perder mi dignidad y más aún mi veracidad. 'Confiesa', 'confiesa' me dicen, como lo hacían en el pasado con herejes y brujas" (114).

Varios de los escritores alemanes más sensibles, de la generación de 1770 a 1820, padecieron severos daños mentales: la carrera de Jacob Michael Lenz, importante dramaturgo, amigo cercano de Goethe, fue destruida por un mal mental. Friedrich Hölderlin pasó las últimas décadas de su vida en una esquizofrenia casi total. Heinrich von Kleist acabó su vida en un pacto suicida; el poeta Clemens Brentano sufrió de melancolía religiosa y una depresión tan grande como la de Cowper. En todos estos casos y en otros, el trabajo creativo más relevante estuvo acompañado de ataques de locura (el caso de los poetas ingleses Christopher Smart y John Clare fue diferente, pues sus obras más memorables las escribieron dentro de una institución psiquiátrica).

Incluso para todos estos escritores $-\mathrm{y}$ para muchos de sus contemporáneos- la demencia fue sólo un ideal y un antideal, una especie de estado que trascendía la conciencia en el que no sólo se escapaba de la obtusa racionalidad, a pesar del riesgo de que dicho estado se saliera de control. Para el artista romántico, la demencia fue más que un receso del pensamiento racional; fue una forma de agudizar la intuición y la sensibilidad. En 1801 Hölderlin escribió: "Verdaderamente la exultante locura es la burla de la burla/ cuando, de repente, el bardo se escucha en la noche sagrada" (Calasso, 2001: 94).

La demencia fue más que una forma de inspiración. Creó toda una lógica y una retórica de lo nocturno y de lo onírico tan poderosa y convincente como la lógica y la realidad de la vida diurna. El 
mundo de los cuentos de Hoffmann es ilustrativo de esta idea: la vida cotidiana coexiste con un mundo de engaño que le da validez al mundo de la intuición y nos hace dudar del mundo real. El reino de las sombras, la magia y la paranoia están siempre al acecho.

En casi todos los grandes poetas del romanticismo (con la excepción de Kleist) la demencia tomó la forma de arrebato religioso. En todos los casos hay una protesta contra la supresión del sentimiento religioso impuesto por la Ilustración, podemos decir, en pocas palabras, que la demencia, tal como la entendemos en este trabajo, estableció una lucha sin tregua contra los filósofos franceses. Esta guerra germinó el resurgimiento religioso después del ocaso del régimen jacobino. Sin embargo, es significativo que ninguno de los poetas románticos tomó la religión como inspiración o como "refugio" -para emplear la palabra con que Blake definió la locura-. En sus inicios como poeta, el londinense Christopher Smart, entre 1749 y 1759, escribió algunos versillos satíricos y didácticos; sus críticos afirman que sus poemas religiosos están bien logrados pero que son poco significativos en el total de su obra. Repentinamente, en 1759, Smart empezó a perseguir a la gente en la calle, para que se arrodillaran con él y elevaran una plegaria a Dios. Su alcoholismo crónico lo llevó a ser confinado en un hospital psiquiátrico. Cuando fue liberado levantó una demanda contra el pueblo de Londres por su falta de piedad. Por su parte, Clemens Brentano, el más exquisito y melodioso de los poetas románticos alemanes, regresó al seno de la Iglesia católica en 1817: durante siete años, por su propia voluntad, se convirtió en secretario de una monja que le dictaba sus experiencias místicas de cuando fue estigmatizada con las heridas de Cristo y plasmó las visiones de la religiosa en una trilogía sobre la vida de Jesús. La conversión de Brentano puso fin a su creatividad poética.

Tampoco las nuevas sectas que inundaron el continente europeo, como la Iglesia metodista, fueron capaces de llenar el vacío intelectual que el triunfo del racionalismo de la Ilustración ocasionó. El 
pensamiento religioso católico o protestante, de los siglos XVIII y XIX fue poco estimulante. La gran excepción fue la obra terrorífica de un demente llamado Joseph de Maistre, cuya filosofía se basaba en la obediencia ciega al arbitrio de la voluntad divina. Para De Maistre la civilización debería estar siempre bajo la amenaza de la pena capital. Su filosofía cínica y contradictoria es una forma de melancolía endurecida por el dogma, cuyo poder emocional explica la curiosa fascinación que ejerció en inteligencias tan sensibles como la de Baudelaire.

La fuerza de De Maistre consistía en que podía encarar lo absurdo sin pena alguna. Por ejemplo, aseveraba que "el ser humano provenía de una sola pareja. Aunque esta verdad ha sido negada como todas las otras, pero ¿a quién le importa?” El siglo XVIII fue el siglo de las contradicciones y del absurdo, por ejemplo, Voltaire escribió al ver un bello atardecer: "Creo en Ti, pero no con la forma del Hijo y de su Santa Madre, eso ya es diferente" (Bloom, 2000: 89). El absurdo fue la influencia más notable del pensamiento religioso a la "locura literaria". Los primeros cristianos tenían como dogma de fe la frase: Credo, quia absurdum (creo porque es absurdo). Lo absurdo significó en la época clásica lo ilógico, lo inexplicable e incomprensible. No fue sino hasta la Ilustración en que se hizo sinónimo de lo ridículo y lo cómico. Los misterios de la religión comenzaron a ser motivo de disputas en el Siglo de las Luces, en el que el entusiasmo religioso fue exonerado de misterios, paradojas y supersticiones. El resultado fue un deísmo desabrido practicado por la gente de Europa. Por algo David Hume dijo al final de su vida que la diferencia entre el deísmo y el ateísmo era una cuestión de énfasis.

$\mathrm{Al}$ perder poder la Iglesia y el pensamiento religioso, los poetas se dieron un banquete parodiando y modificando los textos dogmáticos de la Biblia. Smart escribió Jubilate Agno (Jubileo del Cordero), obra tan excéntrica que ningún editor se arriesgó a publicarla sino hasta 1940. Escrita a imitación del Antiguo Testamento (inspirada en el 
libro de los Salmos y en el de los Profetas), Smart combinó su propia vida con los pasajes de la Biblia. Su estilo es enigmático y hermético, lo cual le da a su obra un sabor profético y demencial. En las siguientes líneas los nombres crípticos de Shefatiah e Ithream se refieren a los dos hijos del rey David:

Dejad que Shefatiah se regocije con el pequeño búho, el cual es el gato alado.

Para que yo sea poseedor de un gato de inigualable belleza, del que aprovecho la ocasión para alabar a Dios Todopoderoso.

Dejad que Ithram se regocije con el pequeño búho, quien entiende lo que profesa.

Para pedir a Dios por los profesores de la Universidad de Cambridge para que vigilen y rectifiquen.

Smart confesó que su método de escritura consistía en golpear las palabras. Las demás poesías de Smart develan una demencia que es más tolerable al lector contemporáneo que al de hace doscientos años. Actualmente nadie, o casi nadie, se escandaliza porque un poeta aluda a la vida de Cristo. En uno de los salmos de Smart encontramos una variante del famoso "El Señor es mi pastor y nada me falta":

El pastor Cristo llegó del cielo

Mi carne y espíritu lo alimentan

Por tanto no estaré privado

De ninguna de mis necesidades naturales.

La locura ayudó a Smart a encontrar una voz original. William Blake, en cambio, inventó su propia religión poniendo de cabeza la escatología cristiana: Satán es el Mesías, el Infierno es el Goce Eterno.

Harold Bloom (2000: 99) escribió que Percy Bysshe Shelley era un poeta profético y religioso cuyas apasionadas convicciones eran agnósticas, y un poeta lírico cuyo estilo era un juego deliberado y 
arriesgado con los límites de la poesía. En consecuencia seguirá siendo polémico, pero ninguna generación de críticos puede prescindir de él. De todos los románticos es el que necesita una interpretación más escrupulosa, una interpretación cuyo contexto debería encontrarse en las tradiciones de la poesía, no en la filosofía o la política. Pero el destino crítico de su poesía ha sido oscurecido por alegoristas que la leyeron como si fuera Platón versificado, o como una apoteosis de Godwin, su suegro y mentor en teoría revolucionaria.

Shelley fue acusado por sus contemporáneos de loco. Por sus biógrafos sabemos que tenía visiones desde que era un niño. Alguna vez "Shelley vio que surgía del mar un niño que palmoteaba llamándolo [...] por las cartas de sus amigos se puede observar que con gran frecuencia percibía este tipo de visiones y de sonidos" (Bloom, 2000: 101). Shelley, como Blake, tuvo una visión profética inspirada en el pensamiento gnóstico. Pensaba que algo malo había sucedido en la época de los profetas. Algo había cambiado el sentido del destino del hombre. Quizá Adán no fuera el primer hombre, ni Jesús el hijo de Dios. Tal vez un espíritu diabólico nos hacía creer eso y nos hacían interpretar erróneamente los símbolos sagrados. La poesía se convierte así en el instrumento idóneo para refundar la cultura occidental, para soldar, de una vez por todas, la unidad de ciencia y religión, razón e instinto. Para Shelley el sentido verdadero de la civilización y de la historia de la humanidad está escondido en los símbolos de la naturaleza. Los hombres hemos leído equivocadamente el mundo, por eso hemos llegado a los niveles más bajos de la inteligencia, parece ser la lección que aprendemos en las descripciones poéticas de Shelley.

Por su parte, Friedrich Hölderlin recurrió al panteón griego no como una decoración poética tradicional sino como una seria representación de las fuerzas naturales universales. En sus himnos y elegías leemos una verdadera aceptación de la existencia de los dioses antiguos. La elegía más reveladora de estas creencias es Pan y vino. Hölderlin creía que el hombre había perdido el contacto con los dio- 
ses y que la locura frenética del éxtasis poético lo volvía a comunicar con los seres divinos:

Amigo mío, llegamos tarde. En verdad los dioses viven pero sobre nuestras cabezas, en otro mundo.

Ellos actúan eternamente allá y parece que se acuerdan de nosotros de si vivimos, porque nos tienen mucha consideración.

No siempre la frágil vasija puede contenerlos.

Sólo de vez en vez la humanidad puede soportar su presencia.

Desde ahora los sońamos en vida. Sin embargo, el que andemos extraviados Ayuda, como el dormir, la necesidad y la noche que nos fortalecen. Incluso a los héroes, criados en cuna de bronce, sus corazones, como en el pasado, similares en fuerza a los divinos, surgen en el trueno. Sin embargo, pienso con frecuencia que es mejor dormir que estar como estoy sin compañía, esperándolos; y mientras tanto no sé qué decir ni hacer, inútilmente están allí los poetas en un tierno vacío. Pero ellos, dices, son como los sacerdotes del vino sagrado de los dioses que vagan de tierra en tierra en la noche sagrada (Rosen, 1998: 123).

Al final de la elegía, Hölderlin confunde intencionalmente a Cristo con el dios del vino, Dioniso. Los dioses están en permanente retirada del mundo: sólo en la noche, en el sueño y en la locura podemos encontrarlos. La demencia del poeta es su pasaporte al mundo perdido.

Ni la poesía de Blake, Hölderlin, Smart o la de Cowper tienen algo en común con el resurgimiento religioso conservador del siglo XIX, sólo Wordsworth y Coleridge se convirtieron en miembros de la Iglesia anglicana y Chateaubriand publicó, en 1802, su influyente libro doctrinario El genio del cristianismo. Por el contrario, Blake y Hölderlin reaccionaron en contra de las enseñanzas de las Iglesias tanto católica como protestante y las rechazaron, además, por su intolerancia y represión sexual y por fomentar la sumisión de los pobres frente a la injusticia social. 
William Blake es el caso más radical del poeta profético, incluso llegó a ser internado en hospitales psiquiátricos en donde "ingresó" en estado "profético". Está documentado que en una estancia en el manicomio Felpham sostenía largas charlas con las sombras de Moisés y otros profetas, Homero, Dante y Milton. Además establecía comunicación con su hermano muerto. Estos espíritus le sugerían los nombres de los personajes de sus poemas: Enitharmon y Golgonooza. Blake tuvo la visión de un jardín del Edén inspirado en las delicias del palacio de Salomón. Thel (probablemente del griego hételo, que quiere decir deseo o voluntad) es un personaje inspirado en la hibridación de la mitología pagana con la mitología británica. Blake da una visión pesimista de la realidad inglesa y una promesa de que encontraremos un nuevo paraíso si logramos escuchar las voces sagradas que se esconden en el universo. Blake es un hermeneuta del mundo simbólico. Como los gnósticos, piensa que el hombre tiene dos almas, una buena y otra mala, la civilización y el poder se han fundado en el alma equivocada, la mala, que suele disfrazarse de buenas intenciones. Lo que debemos descubrir es el alma buena oculta en las cosas malas, sólo así el hombre podrá despertar de su letargo existencial y recobrar el Paraíso. Por eso hay que reinterpretar la Biblia, hay que refundar el cristianismo porque ha sido cambiado en su esencia por el espíritu maligno que triunfó sobre los profetas bíblicos.

En el fondo Blake estuvo más influido por la filosofía de los gnósticos de lo que Harold Bloom imagina. Blake siempre confesó que los cristianos habían eludido los problemas cotidianos desde los tiempos de Jesús con la promesa inútil de una revuelta apocalíptica donde el justo será premiado y el malo castigado. Blake pensaba que la idea del juicio final era una de las perversas mentiras de la alteración de la historia. Para el poeta inglés, las instituciones, las leyes, religiones e Iglesias no eran más que bromas y trampas de una estafa milenaria instaurada por el alma perversa de la humanidad. Para Blake, el trance visionario es el triunfo del alma sobre el cuerpo, de la inteligencia 
sobre lo corporal; al vencer lo espiritual a lo corporal se puede pensar en que vemos el mundo tal y como es.

El poeta inglés Wallace Stevens escribió en La figura del joven como poeta viril una especie de manifiesto del éxtasis y locura poéticos del romanticismo:

[...] si dijéramos que la idea de Dios es solamente una idea poética y que nuestras nociones de cielo e infierno son meramente poesía no conocida bajo ese nombre, aun cuando sea poesía que nos implica vitalmente, la sensación de rescate, de liberación, de una perfección tocada, de una vocación a fin de que todos los hombres puedan conocer la verdad y de que la verdad pueda hacerlos libres; si dijéramos estas cosas y fuéramos capaces de reconocer al poeta que alcanzó a Dios y lo colocó en su silla en el ciclo rodeado de toda su gloria, el poeta mismo todavía en el éxtasis del poema que ha cumplido completamente su propósito, nos parecería, sea viejo o joven, en harapos o con hábitos ceremonial, un hombre que necesitaba lo que ha creado, entonando los himnos de alegría que siguieron a su creación (Bloom, 2000: 43).

Por muchos años la preocupación de filósofos y poetas fue conciliar la razón y el instinto. Por ejemplo, en la Inglaterra de William Blake el fantasma de la Revolución es una de las invocaciones del dios Pan. Tal como lo escribió Baudelaire, muchos años después, junto a la idea de la Revolución llegó el hálito de Dioniso a París. El furor que inundó las calles de la Ciudad Luz fue calificada como una bacanal. Este mismo furor viajó hasta Londres y contagió a poetas y revolucionarios. Testimonio de la peste báquica quedó en tres libros de tres románticos ingleses: El matrimonio del cielo y el infierno de Blake, El preludio de Wordsworth y Prometeo desencadenado de Shelley. El Londres de la última década del siglo XVIII y la primera del XIX es el mostrado en el poema de Blake que lleva ese título en Cantos de experiencia: una ciudad en la que las tradiciones de petición y asamblea han sido negadas regularmente. Un país ya sacudido por la guerra y los anárquicos ciclos económicos estaba comenzando a experimentar 
la inquietud social que había subvertido el orden social francés, y la clase dirigente británica respondía a este desafío con una represión viciosa y sumamente efectiva. El racionalismo del siglo XVIII rompió el nudo gordiano entre el hombre y el mito, los símbolos sagrados se refugiaron en la poesía de los escritores visionarios que revelan el mundo secreto que pervive en el inconsciente y emerge escondido en el sueño. Son continuadores de esta tradición: Charles Baudelaire, Arthur Rimbaud, Henri Michaux, Wallace Stevens y muchos otros que se resisten a que mueran los símbolos arcanos de la poesía kerygmática.

Francisco Hernández reanudó con su libro un tipo de discurso poético poco frecuentado en la literatura mexicana, claro, con sus honrosas excepciones, y que es un discurso que acerca tres saberes: la poesía, la filosofía y la psicología. El hablar de poesía, locura, delirio, misticismo, la revelación del absoluto es uno de los filones más interesantes del irracionalismo poético.

\section{Bibliografía}

Berman, Morris, 2001, El reencantamiento del mundo, trad. Rally Bendersky y Francisco Hunneus, Cuatro Vientos, Santiago de Chile. , 2001, Cuerpo y espiritu. La historia oculta de Occidente, Cuatro Vientos, Santiago de Chile.

Bloom, Harold, 1997, Presagios del milenio. La gnosis de los ángeles, el milenio y la resurrección, trad. Damián Alou, Anagrama, Barcelona.

, 1999a, La compañía visionaria. William Blake, trad. Mariano Antolin Ratto, Adriana Hidalgo, Buenos Aires. ,2000, La compañia visionaria. Lord Byron y Shelley, trad. Mariano Antolin

Ratto, Adriana Hidalgo, Buenos Aires.

,2003, La compañia visionaria. Wordsworth, Coleridge y Keats, trad. Pablo Gianera y Edgardo Russo, Adriana Hidalgo, Buenos Aires.

Calasso, Roberto, 1994, Las bodas de Cadmo y Harmonía, trad. de Joaquín Jordá, Anagrama, Barcelona. 
, 2001, La literatura y los dioses, trad. Edgardo Dobry, Anagrama, Barcelona.

,2004, La locura que viene de las musas, trad. Teresa Ramírez Vadillo, Sexto Piso, México.

Frye, Northrop, 1977, Anatomía de la crítica, trad. Edison Simons, Monte Ávila, Caracas.

, 1996, Poderosas palabras, trad. Claudio López Lamadrid, Muchnik, Barcelona.

Gadamer, Hans Georg, 1997, Mito y razón, trad. José Francisco Zúñiga García, Paidós, Barcelona.

1993, Poema y diálogo. Ensayos sobre los poetas alemanes más significativos del siglo XX, trad. Daniel Najmías y Juan Navarro, Gedisa, Barcelona.

Hernández, Francisco, 1996, Poesía reunida, presentación de Vicente Quirarte, UNAM-Ediciones del Equilibrista, México.

Nerval, Gérard de, 1998, Aurelia, pról. Xavier Villaurrutia, trad. J. Sánchez Sáinz, Coyoacán, México.

Rosen, Charles, 1998, Romantic Poets, Critics, and Other Mad Men, Harvard University Press, Cambridge. 